\title{
Effect of hyoscine-n-butyl bromide (Buscopan) rectal suppository in active phase of labour in primigravida
}

\author{
Namdeo T.A. ${ }^{1}$, Jeevitha K.J. ${ }^{2}$, Ganapathy P. ${ }^{3}$ \\ ${ }^{1}$ Dr. Tupkar Amruta Namdeo, Consultant Obstetrician and Gynaecologist, Mauli Multi-speciality Hospital, Pune, \\ Maharashtra, India. ${ }^{2}$ Dr. Jeevitha K. J., Assistant Professor, Department of OBG, Velammal Medical College Hospital \& \\ Research Institute, Madurai, Tamil Nadu. ${ }^{3}$ Dr. Prabha Ganapathy, Head of the Department of OBG, Public Health \\ Centre, Chennai, Tamil Nadu India.
}

Corresponding Author: Dr. Jeevitha K.J., MBBS, DNB (OBG), MNAMS, Plot No. 768, $1^{\text {st }}$ East Cross Street, Anna Nagar, Madurai- 625020, Tamil Nadu, India. E-mail: jeevithakj@yahoo.co.in

\begin{abstract}
Introduction: Labour is a physiological process characterized by onset of uterine contractions leading to progressive increase in frequency, intensity and duration of uterine contractions, effacement and dilatation of cervix with descent of foetus through birth canal resulting in delivery of foetus with placenta and membranes. Hyoscine butyl bromide is most commonly used in labour room and has variable results in both primigravida and multigravida. Aim and Objective: 1. To evaluate the efficacy of Hyoscine-n- butyl bromide (buscopan) suppository in the active phase of labour in a primigravida.2. To evaluate the maternal and fetal complications of using the buscopan suppository. Materials and Methodology: Primigravida with gestational age 37 completed weeks - 40 weeks admitted in the labour ward with spontaneous onset of labour or induced labour who-fulfil the inclusion \& exclusion criteria were randomly selected in this study after taking informed consent. Study group: 150 pregnant women at the initiation of active phase allowed forlabour with instillation of single dose of Buscopan rectal suppository (10 $\mathrm{mg}$ ) in active phase for cervical dilatation. Control group: 150 pregnant women at the initiation of active phase allowed forlabour without any drug for cervical dilatation. Study Design: Prospective case control study. Result: The mean duration of active phase of labour in study group is 3 hours 10 minutes \& in control 5 hours 44 minutes. The difference between both the groups was statistically significant ('p' value $<0.001$ ). No significant difference in maternal and fetal complications between study group and control group. Conclusion: Buscopan suppository was very effective in reducing the duration of active phase of labour by promoting cervical dilatation. There was no significant second or third stage complication with the use of the drug. No untoward side effects were noted in the mother or foetus.
\end{abstract}

Keywords: Buscopan, Cervical dilatation, Hyoscine-N-butyl bromide, Labour

\section{Introduction}

The stages of labour are the most dynamic one and require very careful observation. Any method which shortens the duration of labour without any complication is always welcomed by patient as well as obstetrician [1]. For obstetricians who are present at delivery nothing is more disturbing than the prolonged labour even though abnormal troublesome events may not accompany it. This is also the case for the expectant mother herself who suffers from increased fatigue of labour, anxiety \& worry caused by prolonged labour [2]. In prolonged labour, the mother is exposed to

Manuscript received: $14^{\text {th }}$ July 2019

Reviewed: $24^{\text {th }}$ July 2019

Author Corrected: $30^{\text {th }}$ July 2019

Accepted for Publication: $6^{\text {th }}$ August 2019 higher risk of infection, dehydration and ketosis \& unrecognized obstructed labour. The foetus is exposed to danger of infection, asphyxia \& excessive cranial moulding. The prolonged labour also made way for certain remote complications like genital prolapse, disability of bladder, sphincter mechanisms, pelvic infections and certain late psychological sequel which affected the mother in her attitude towards further child bearing [3].

Hyoscine -N- Butyl Bromide is a semisynthetic derivative compound of belladonna alkaloid. It is a labour stimulant which was introduced by $\mathrm{CH}$ Boehringer Sohn Ingelhim Am Rhein Germany [4]. It is derived from a shrub (Dubosia) found in Australia. 


\section{Original Research Article}

Hyoscine $-\mathrm{N}$ - butyl bromide smoothens the passage of labour by shortening the duration of active phase of first stage of labour without any untoward foetal and maternal effects. Hyoscine $-\mathrm{N}$ - Butyl Bromide was introduced which was an effective antispasmodic with a high safety profile. Hyoscine $-\mathrm{N}$ - Butyl Bromide has the ability to mitigate spasm of cervix uteri and lower part of corpus uteri. It inhibits the cholinergic transmission in the synapses of the intramural parasympathetic ganglia.

The advantages of Buscopan: $[2,4]$

1. Specific antispasmodic action on abdominal and pelvic organs.

2. Absence of undesirable side effects on salivary gland, sudoriferous glands and optical organs.

3. The contractions are in no way affected, but due to better co-ordination of contractions, pace of cervical dilatation is increased.

4. It has a peripheral anticholinergic action but no central action as it does not cross the blood brain barrier.

The side effects are [4]: Dryness of mouth, tachycardia, blurring of vision and drowsiness.

The rationale of using rectal suppository: Rectum has a rich blood supply and lymph supply; drugs can cross the rectal mucosa like other mucosa. Gastric irritation is avoided; by using a suitable solvent duration of action can be controlled. Partial bypass of hepatic metabolism is possible. It has faster absorption than oral route. It is easy procedure to administer the drug.

Pharmacokinetics $[2, \mathbf{4}, \mathbf{6}]$ : Duration of action is 5-10 minutes of administration. Following oral administration $2-8 \%$ is absorbed. It appears in the bile in 2-6 hours and in the urine in 6-12 hours. Following administration $2 \%$ is excreted in the urine and $90 \%$ in the faeces. Its plasma half-life is 8 hours.

\section{Materials and Methods}

It is a prospective study conducted in the Department of Obstetrics and Gynaecology at Public health centre, West Mambalam, Chennai, for a period of 6 months from June 2017 to December 2017.

Primigravida women with gestational age 37 completed weeks - 40 weeks admitted in the labour ward with spontaneous onset of labour or induced labour whofulfil the inclusion \& exclusion criteria were randomly selected in this study after taking informed consent.
Study group: 150 pregnant women at the initiation of active phase allowed forlabour with instillation of single dose of Hyoscine-N-butyl bromide (Buscopan) rectal suppository $(10 \mathrm{mg})$ in active phase for cervical dilatation.

Control group: 150 pregnant women at the initiation of active phase allowed forlabour without any drug for cervical dilatation.

Study Design: Prospective case control study.

Inclusion Criteria: Primigravida, gestational age- 37 completed to 40 weeks, cephalic presentation, induced or spontaneous labour, singleton pregnancy, membranes intact/ ruptured, and drug given at $3-4 \mathrm{~cm}$ of cervical dilatation with regular uterine contractions.

Exclusion criteria: Post term, foetal distress, previous LSCS, malpresentation, cephalopelvic disproportion, multiple pregnancies, severe anaemia, cardiac disease, severe Pre-eclampsia / eclampsia preterm pregnancies, antepartum haemorrhage, cord prolapse.

Hyoscine N-butyl bromide suppository (10 mg) single dose was administered at $3-4 \mathrm{~cm}$ cervical dilatation with regular uterine contractions at the initiation of active phase of labour in study group.

Patient was reassessed by doing vaginal examination every 2 hours or earlier, if: Rupture of membranes occurred or patient started bearing down.

Fetal wellbeing was confirmed by cardiotocograph. Labour was monitored clinically by Partograph. Time was recorded at 3-4 $\mathrm{cm}$ of cervical dilatation that is at the time of initiation of active phase and at full cervical dilatation that is the end of active phase.

Duration of active phase of labour calculated. Continuous electronic foetal heart rate monitoring was done for all patients in active phase of labour. Patients were encouraged to keep their bladder empty.

Any maternal side effects of the drug such as tachycardia, dryness of mouth, flushing, headache, nausea, vomiting and hypotension were noted and treated accordingly.

After delivery of placenta, cervix and vagina were inspected to exclude any trauma to cervix. After delivery, fetal well being assessed by Apgar score at 1 minute and 5 minutes and other neonatal complications noted if any. 
The following parameters were recorded: Duration of active phase of first stage of labour, Apgar score (at 1 minute $\&$ at 5 minutes.), maternal and perinatal complication

Statistical Analysis: The collected data was analysed with Statistical Presentation System Software (SPSS) for Windows, Version 17.0, the frequency analysis and percentage analysis were used to find the distribution of data, to describe about the data, mean and S.D. was used. To find the significance between the study and control group, Mann Whitney test, Independent Student $\mathrm{T}$ test and for the nominal data Chi square test was used.

In all the above statistical tools probability value $\mathrm{p}<$ 0.05 is considered as significant.

\section{Result}

The mean age in study group was 24.41 years and in control group was 24.72 years and all were primigravida in both groups. The mean gestational age was 38.72 weeks and in control group was 38.69 weeks, thus selection of patients in both groups were similar [Table 1]

The average duration of active phase of labour in study group was 189.79 minutes (3hours) and in control group was 344.08 minutes ( 5 hours), thus it is statistically significant $(\mathrm{p}<0.00)$ [Table 2]. Rate of caesarean section in study group $25(16.6 \%)$ and in control group 30(20\%). No significant difference in second and third stage of labour complications in both groups. No significant difference in maternal andfetal complications in both groups. [Table 3]

Table-1: demographic profile \& results.

\begin{tabular}{|l|l|c|c|}
\hline & & Study group & Control \\
\hline & & (n-125) & Group (n-120) \\
\hline Mean age & & 24.41 years & 24.72 years \\
\hline $\begin{array}{l}\text { Paritymean gestational age } \\
\text { (in weeks) }\end{array}$ & & $\begin{array}{c}\text { Primigravida } \\
38.72\end{array}$ & $\begin{array}{c}\text { Primigravida } \\
38.69\end{array}$ \\
\hline $\begin{array}{l}\text { Mean duration of active phase of } \\
\text { labour. (in minutes) }\end{array}$ & & $189.79 \pm 64.67$ & $344.08 \pm 82.28$ \\
\hline Mode of delivery & Normal vaginaldelivery & 115 & 105 \\
\hline & Instrumentalvaginaldelivery & 10 & 15 \\
\hline & Caesareansection & 25 & 30 \\
\hline Indication ofcaesarean Section & Foetal distress & 15 & 14 \\
\hline & Arrest ofcervicaldilatation & 4 & 6 \\
\hline & $\begin{array}{l}\text { Cephalopelvicdisproportion } \\
\text { Diagnosedduring activeLabour }\end{array}$ & 6 & 10 \\
\hline
\end{tabular}

\begin{tabular}{|c|c|c|c|c|c|}
\hline \multirow{3}{*}{$\begin{array}{l}\text { Second stage } \\
\text { complications }\end{array}$} & Foetal distress & \multicolumn{2}{|r|}{3} & \multicolumn{2}{|c|}{7} \\
\hline & Arrest ofdescent & \multicolumn{2}{|r|}{2} & \multicolumn{2}{|c|}{3} \\
\hline & Shoulderdystocia & \multicolumn{2}{|r|}{3} & \multicolumn{2}{|c|}{2} \\
\hline \multirow[t]{3}{*}{ Third stage complications } & Atonic PPH & \multicolumn{2}{|r|}{7} & \multicolumn{2}{|c|}{9} \\
\hline & Cervical tears & \multicolumn{2}{|r|}{7} & \multicolumn{2}{|c|}{9} \\
\hline & RetainedPlacenta & \multicolumn{2}{|r|}{2} & \multicolumn{2}{|c|}{2} \\
\hline \multirow[t]{4}{*}{ Neonataloutcome } & APGAR score & $\begin{array}{c}\text { At } 1 \\
\text { minutes }\end{array}$ & At 5 minutes & $\begin{array}{c}\text { At } 1 \\
\text { minutes }\end{array}$ & $\begin{array}{c}\text { At } 5 \\
\text { minutes }\end{array}$ \\
\hline & $0-3$ & 0 & 0 & 0 & 0 \\
\hline & $4-6$ & 3 & 0 & 6 & 1 \\
\hline & $7-10$ & 147 & 150 & 144 & 149 \\
\hline \multirow[t]{5}{*}{ Maternal sideeffects } & Maternaltachycardia & \multicolumn{2}{|r|}{7} & \multicolumn{2}{|c|}{6} \\
\hline & Vomiting & \multicolumn{2}{|c|}{13} & \multicolumn{2}{|c|}{10} \\
\hline & Dryness of mouth & \multicolumn{2}{|r|}{4} & \multicolumn{2}{|c|}{2} \\
\hline & Flushing of skin & \multicolumn{2}{|r|}{1} & \multicolumn{2}{|c|}{1} \\
\hline & Nausea & \multicolumn{2}{|c|}{12} & \multicolumn{2}{|c|}{9} \\
\hline
\end{tabular}


Original Research Article

Table-2: Duration of Active phase of labour

\begin{tabular}{|c|c|c|c|c|}
\hline \multirow{2}{*}{$\begin{array}{l}\text { Duration of active } \\
\text { Phase of labour }\end{array}$} & \multicolumn{2}{|c|}{ Study group } & \multicolumn{2}{|c|}{ Control group } \\
\hline & $(n=125)$ & & $(n=120)$ & \\
\hline & Total & $\%$ & Total & $\%$ \\
\hline & Number & & Number & \\
\hline$<3$ hours & 65 & 52.4 & 4 & 3.3 \\
\hline 3-4 hours & 10 & 32.3 & 10 & 8.2 \\
\hline 4-5 hours & 12 & 9.7 & 25 & 20.5 \\
\hline 5-6 hours & 2 & 1.6 & 34 & 27.0 \\
\hline$>6$ hours & 6 & 4.0 & 49 & 41.0 \\
\hline Mean time(in minutes) & 189.79 & & 344.08 & \\
\hline S.D. & 64.67 & & 82.28 & \\
\hline 'P' value & $<0.001$ & & & \\
\hline
\end{tabular}

Table-3: Maternal complications

\begin{tabular}{|l|c|c|c|c|}
\hline \multicolumn{1}{|c|}{ Maternal side effects } & \multicolumn{2}{|c|}{$\begin{array}{c}\text { Ctudy group } \\
\text { (n-150) }\end{array}$} & Total group & \% \\
\hline & Total group & \% & 6 & 4 \\
\hline Maternal tachycardia & 7 & 4.66 & 10 & 6.66 \\
\hline Vomiting & 13 & 8.66 & 2 & 1.33 \\
\hline Dryness of mouth & 4 & 2.66 & 1 & 0.66 \\
\hline Flushing of skin & 1 & 0.66 & 9 & 6 \\
\hline Nausea & 12 & 8 & & \\
\hline 'P' - value & & & 0.998 & \\
\hline
\end{tabular}

\section{Discussion}

Buscopan has been used as drug to reduce or shorten the duration of labour in some parts of the world, but there is few literature of review to relate with their efficacy and use in labour.

In this study the initial cervical dilatation at which drug was given, was 3-4 cm. In most of the studies drug was administered at $3-4 \mathrm{~cm}$ of cervical dilatation, which was comparable to the presentstudy [7, 8, 9, and 11]. In the present study [Table 1], the mean duration of active phase of labour was 3 hours 10 minutes (189.79 minutes) which was comparable to the studies by Somayeh etal [12] and DayaSirohwaletal [6].Similar results were found by Samuels et al [13]. Thus with the use of drug, duration of active phase of labour was significantly reduced [Table 2]. Buscopan primarily acts on cervix and not to increase uterine contractility. This is important as it proves it has little effect on second and third stage of labour thus avoids complications to mother and foetus [13]. Hyoscine butyl bromide has been used to shorten the duration of labour, whereas its analgesic property is probably negligible in context of labour [14]. In contrast Al Dohami stated Hyoscine is a muscarinic antagonist that acts on cervix and has no effect on duration of labour or cervical dilatation [15].

For fetal distress and arrest of descent at full cervical dilatation, instrumental vaginal delivery was conducted. Shoulder dystocia both in study group and control was due to big baby (birth weight $>3.5 \mathrm{~kg}$ ). But there was no significant difference in $2^{\text {nd }}$ stage complications between study and control group. So there was no effect of the drug on $2^{\text {nd }}$ stage complications. There was no significant $2^{\text {nd }}$ stage complication in this present study ('p' value-0.535) which was comparable to the study done by Qahtani [16], Daya Sirohiwaet. al [6] and Samuel [13] which observed no complications. Difference between the study group and control was not statistically significant ( $\mathrm{p}$ value- 0.953 , calculated by chi square test) for third stage complication [ Figure 2], 
so there was no significant $3^{\text {rd }}$ stage complication in this present study which was comparable to the study done by Daya Sirohiwaletal $[6,13]$ which also showed no complications. At no time in the period of gestation is the offering aid for purpose of foetal outcome so concentrated as it is during labour. Hence it has to be ensured that the drugs which are used for hastening labour must be free from foetal side effects and do not adversely affect the fetal outcome.

Among study group, no neonate had APGAR between $0-3$ at 1 minute $\&$ at 5 minutes. $2 \%$ of neonates had APGAR between 4-6 at 1 minute \& no neonates at 5 minutes. Among cases 98\% had APGAR between 7-10 at $1 \mathrm{~min} \& 100 \%$ at 5 minutes. APGAR of the babies at 1 minute ('p' value - 1) and 5 minute ('p' value- 0.317 , calculated by Mann Whitney test) showed that the drug used had no adverse effects on the foetus.

In the present study the drug did not have adverse effects onthe neonates. Similar outcome was obtained by study done by Kirimet al [17]. Tewari et.al [11] in their study concluded that the drugs did not interfere with utero-placental circulation.

In the present study, atropine side effects were seen in the test group. The most common side effect seen was nausea and vomiting. Difference between the study group and control [Table 3] was not statistically significant ( $p$ value -0.998 calculated by Chi square test). So in the present study the drug did not have any adverse maternal side effects, which is comparable to study supported by Samuel et al [13].

Limitations: The sample size of the present study was 100 in study group and 100 in control group; though small in number, results obtained were similar to previous studies. Study with larger sample size and longer duration can compare the effects on maternal and fetal outcome. Another limitation was there were limited reviews of literature similar to this topic.

\section{Conclusion}

Painless child birth has been the cherished desire of every women and the constant aim of the obstetrician. The stress and strain results in the reduction in the capacity of pelvic musculature to relax causing subclinical dystocia.

Various forms of pharmacological interventions have helped in shortening the duration of labour by augmenting the cervical dilatation, making the child birth safe.

\section{Original Research Article}

\section{What the study adds in the existing knowledge?}

Hyoscine-N-butyl bromide suppository was very effective in reducing the duration of active phase of labour by promoting cervical dilatation.

There were no significant second or third stage complications with the use of the drug. No untoward side effects were noted in the mother or foetus.

Hyoscine-N- butyl Bromide suppositories are safe and effective in reducing the duration of labour. Definitely it will reduce the incidence of prolonged labour due to delayed cervical dilatation and maternal and fetal complications associated with prolonged labour.

Because of its convenience of administration (as rectal suppository), it can be comparable alternative in rural set-ups where trained medical personnel may not be available most of the times.

Author's Contribution:Dr. Amruta T.N. helped with study protocol, collection of data and preparation of the study article. Dr. Jeevitha. K. J. helped in drafting the protocol, preparation of article and final document preparation with necessary modifications of the article for publication.Dr. Prabha G.helped with critical revision of the article.

\section{Compliance with ethical standards}

Conflict of interest: The author declares that there is no conflict of interest.

Ethical Approval: Institutional ethical committee clearance was obtained for the study.

Informed consent: Informed consent was obtained for all patients for being included in the study.

Funding: Nil, Conflict of interest: Nil Permission from IRB: Yes

\section{References}

1. Gary CF, Leveno KJ, Bloom SL, Huth JC. Williams textbook ofobstetrics.23 ${ }^{\text {rd }}$ ed, New York, McGraw Hill, 2010; 136-160,384-406,412-430.

2. Sarala G, Vinita. Textbook of Mudaliar and Menonsclinical Obstetric, $10^{\text {th }} \mathrm{ed}$, Chennai Orient Longman 2005;83-115.

3. Shirish ND, Chakravarthy S, Daftary GS. Holand and Brewsmanual of Obstretics. New Delhi 2002; 152 


\section{Original Research Article}

4. Jitendra H, Ainapure S. Hyoscine Butyl bromide Suppositories:Indian Medical Gazette, .2000; 217-219.

5. WICK H. [Buscopan]. Naunyn Schmiedebergs Arch Exp PatholPharmakol. 1951;213(6):485-500.

6. Sirohiwal D, Dahiya K, De M. Efficacy of hyoscine$\mathrm{N}$-butyl bromide (Buscopan) suppositories as a cervical spasmolytic agent in labour. Aust NZJ Obstet Gynaecol. 2005; 45 (2): 128-9.doi: 10.1111/j. 1479-828X.2005. 00359.x

7. Sharma JB, Pundir P, Kumar A, Murthy NS. Drotaverine hydrochloride vs. valethamate bromide in acceleration of labor. Int J Gynecol Obstet. 2001;74(3): 255-60. doi: 10.4103/0976-500X.64528

8. Kaur D, Kaur R. Comparision of Drotavarine and epidosin in first stage of labour, J Obstet Gynaeccol India. 2003;53(5):449-452.

9. Mishra SL, Toshniwal A, Banerjee R. Effect of drotaverine on cervical dilatation-a comparative study with epidosin (valethamate bromide). J Obstet Gynecol India. 2002;52(3):76-79.

10. Vellanki VS. Comparison of Busscopan and Epidpsinoncervical dilation in labour. Global J Med Res. 2010;10(2):18-21.

11. Tewari K, Jabeen R, Sabzposh MA, Rabbani T. Comparison of Hyoscine-Butylbromide and Valethamate Bromide in shortening the duration of labour. Ind Med Gaz. 2003;137(1):15-19.doi: 10.2147/ TCRM.S16415
12. Makvandi S, Tadayon M, Abbaspour M. Effect of hyoscine-N-butyl bromide rectal suppository on labor progress in primigravid women: randomized doubleblind placebo-controlled clinical trial. Croatian Med Journal. 2011;52(2):159-163. doi: 10.3325/cmj. 2011. 52.159

13. Samuels LA, Christie L, Roberts-Gittens B, Fletcher $\mathrm{H}$, Frederick J. The effect of hyoscine butylbromide on the first stage of labour in term pregnancies. BJOG. 2007;114(12): 1542 1546. Epub 2007. doi:10. 1111/j. 1471- 0528.2007.01497.x

14. Sekhavat L, Karbasi SA, Fallah R, Mirowliai M. Effect of hyoscine butylbromide first stage of labour in multiparus women. Afr Health Sci. 2012;12(4):408-411.

15. Al Dohami HS, Al Matari FI. Is Buscopan (hyoscine-N-butylbromide) effective in shortening labor. In12th Annual General Meeting of the Saudi Obstetric and Gynaecological Society 2002 Apr 17 (pp. 17-18).

16. Qahtani NH, Hajeri FA. The effect of hyoscine butylbromide in shortening the first stage of labor: A double blind, randomized, controlled, clinical trial. Ther Clin Risk Manag. 2011;7:495-500. doi: 10.2147/ TCRM. S16415. Epub2011.

17. Kirim S, Asicioglu O, Yenigul N, Aydogan B, Bahat N, Bayrak M. Effect of intravenous hyoscineN-butyl bromide on active phase of labor progress: a randomized double blind placebo controlled trial. J Matern Fetal Neonatal Med. 2015;28(9):1038-1042. doi: 10.3109/14767058.2014.942628. Epub 2014.

\section{How to cite this article?}

Namdeo T.A, Jeevitha K.J, Ganapathy P. Effect of hyoscine-n-butyl bromide (Buscopan) rectal suppository in active phase of labour in primigravida. Obs Rev: J obstet Gynecol 2019;5(3):147-152.doi:10.17511/joog.2019.i03.04. 